\title{
AMPHIBIANS AND REPTILES
}

\section{CRANIODICHOTOMY INACROTALUS: A TWO-HEADED PRAIRIE RATTLESNAKE NEAR LEADER, SK}

ALEXANDRA REID, 108C-906 Duchess St., Saskatoon, SK S7K 6K3 E-mail: <reida@shaw.ca>

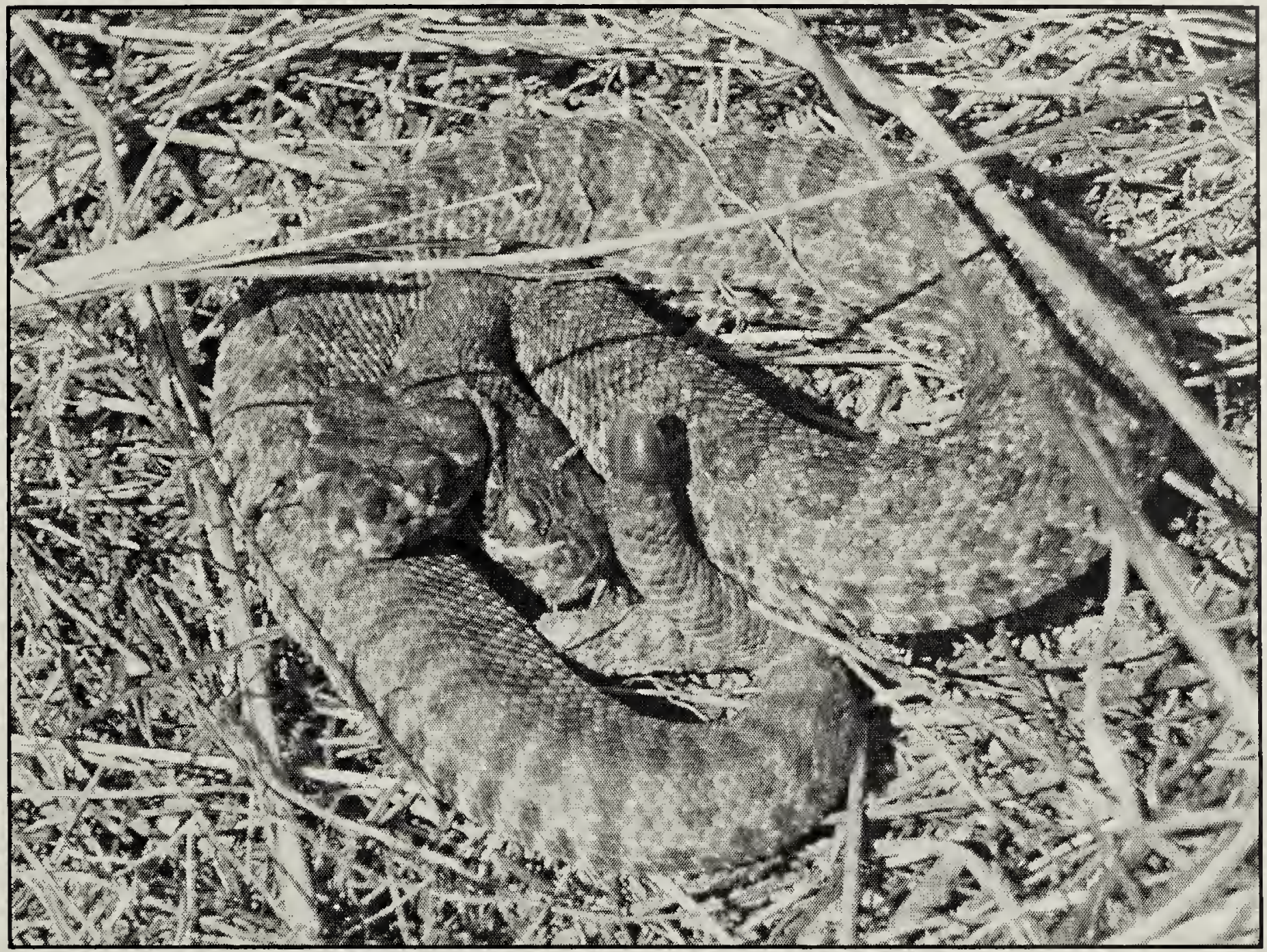

Figure 1. Two-headed Prairie Rattlesnake photographed on October 3, 2004 near Leader, SK. The "pre-button" rattle has only one segment, indicating that this individual is recently born as it has not had its first post-partum shed.

A. Reid

Prairie Rattlesnakes, Crotalus viridis, are a rare sight on the Saskatchewan prairies. They occur only in the southwestern to south central portion of the province, and their range has been reduced by development of the prairies for agriculture. People's reactions to rattlesnakes vary from avoidance to killing snakes on sight to seeking out dens and destroying them, despite the rattlesnake's protection under the Saskatchewan Wildlife Act. ${ }^{5}$ Thus, seeing Prairie Rattlesnakes in the wild is a priviledge not often granted.

My friends Kattia Carrasquilla, Vanan Kesavan and I have located several denning sites just outside of Leader, SK, generally all within a kilometre or two of the South Saskatchewan river. Dens are critical to rattlesnake survival 
as they provide protection from the harsh winter climate for these snakes, which brumate below the frost line. ${ }^{5}$ (Brumation in reptiles is a state of reduced metabolism triggered independently of environmental temperature.) Shortly after emerging in late April or early May, the non-breeding females and males disperse several kilometres from the den, but gestating females stay close to the denning site until they give birth in early August ${ }^{5}$. Thus, on October 3rd, 2004 we were not particularly surprised to see two large rattlesnakes and several neonates (recently-born snakes) near the South Saskatchewan river in the general area of Leader. ${ }^{3}$ (See back cover.) Predictably, as we approached, the snakes rattled their tails, uncoiled and began to disappear down into the den entrance. (Figure 2)
This is when Kattia began screaming "It has two heads!" and pointed at the ground. What Vanan and I had dismissed as two neonates basking together, uncoiled to reveal a single neonate with two heads. (Figure 1) To take a closer look we quickly pinned it to the ground with snake hooks, long straight pieces of metal with a curve at the end, used for handling venomous snakes from a safe distance. The neonate was only $26 \mathrm{~cm}$ long and dark with a somewhat obscured pattern, indicating it was about to shed its skin. It appeared similar in length to other neonates, but was slightly thicker throughout the body.

The two heads were joined just behind the base of the skull and each appeared to be fully functional: both

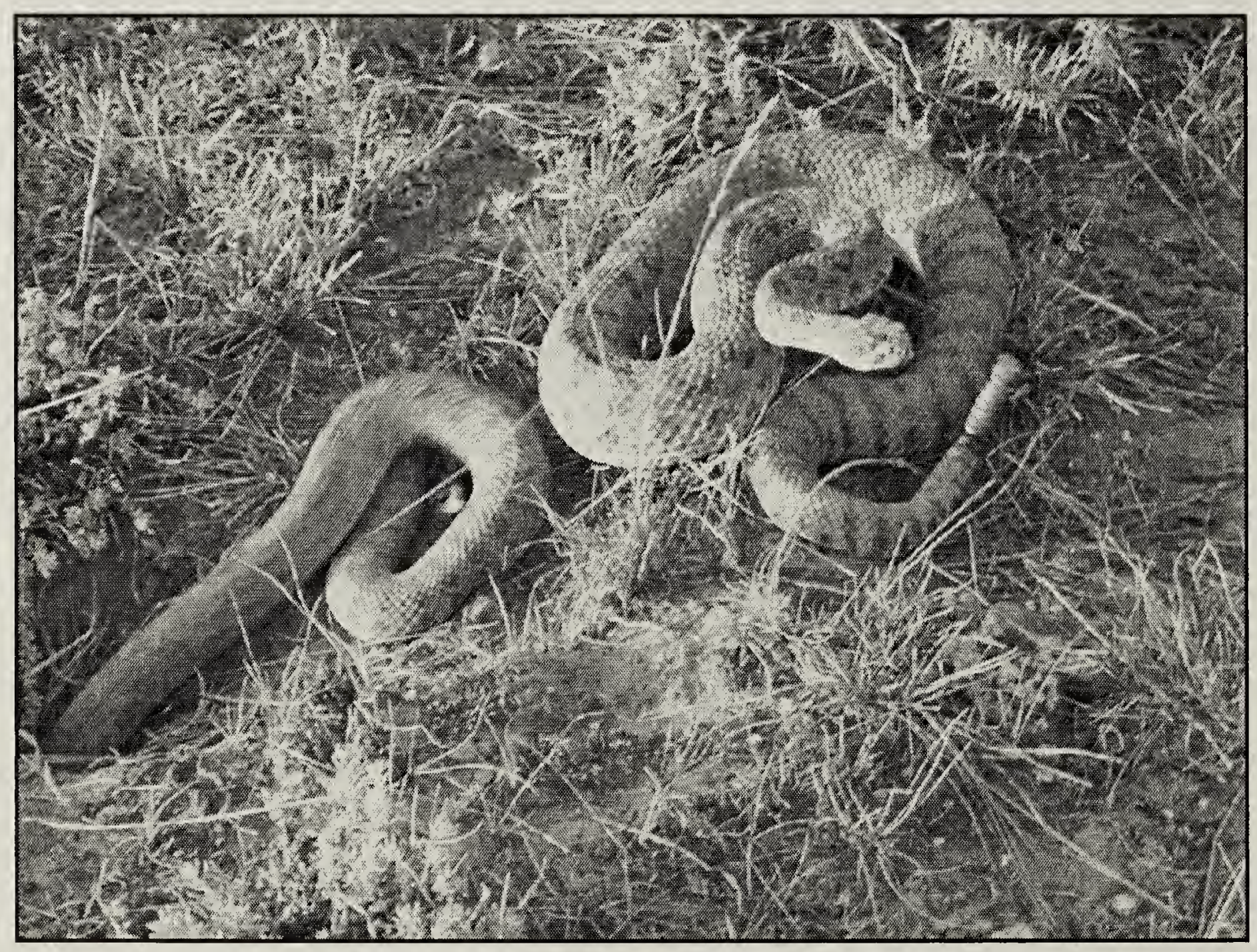

Figure 2. Adult prairie rattlesnakes disappearing into a den entrance when disturbed, October 2, 2004.

A. Reid 
sets of eyes appeared to focus, both tongues were flicking actively, and both mouths were certainly capable of biting. When the snake was released from the hook, the right-hand head seemed predominantly to control movement; the snake was generally coiled so that its right head faced us. The left head was still conscious, however, and the tongue flicked actively in our general direction. This snake was capable of coiling and tail rattling, but as it disappeared into the den it was noted to have an odd form of movement, a rather inching, sidewinding sort of locomotion that seemed weaker than the fluid movement of other neonates observed earlier in the day.

The next day, we captured the twoheaded neonate outside the same den and kept it in captivity until it died on approximately February 21 st. I kept it in a 10 gallon glass terrarium on astroturf, with a shallow water dish and cardboard hidebox. The temperature was maintained between $26^{\circ} \mathrm{C}$ and $30^{\circ} \mathrm{C}$. Food was offered in the form of domestic crickets (Acheta domestica) and newborn domestic mice (Mus musculus domesticus). While both heads tracked prey items and successfully envenomated, the right head was the most active in these hunting episodes. Successful attack of prey items indicated the snake was able to detect both odor and heat of the prey. However, the snake never consumed these prey items. The snake also exhibited a form of locomotion that was odd for a rattlesnake: it often moved sideways but exhibited small tremors that were especially noticable around the front of the body. When agitated, it did rattle its tail, producing a normal sound, and seemed to be able to target the source of danger, which was generally myself. It shed its skin twice. Each episode proceeded normally except it was unable to cast the skin without assistance in the form of warm water soaking and manually peeling the skin away, particularly around the heads. After each shed, a segment was added to the rattle. The snake steadfastly refused food, and became lethargic shortly before its death. I was away when it died and found it approximately five days after its death, so a certain amount of decay had taken place.

The snake was frozen until a necropsy could be performed. It had grown approximately $2.5 \mathrm{~cm}$ in length since capture. The radiograph (Figure 3 ) shows a grossly normal spine except where the two heads meet at an abnormally large vertebra, roughly hexagonal in shape. The left head had 6 vertebrae before the fusion while the right head had 8. Dissection revealed that the two esophagi fused just behind the joining of the two heads. The esophagus was normal between the point of fusion and the stomach. The intestine then separated again where it joined the stomach, but fused after approximately $2.5 \mathrm{~cm}$. The rest of the intestine appeared normal. The two wind pipes (trachea) were separate; each head/neck had a separate respiratory and cardiovascular system. The left side generally seemed smaller and less developed. The heart on the left was smaller and carried little blood. The left lung and airsacs were also smaller. The right lung and airsac were well developed. We could not assess the functional capacities of these duplicated organs, but this situation is similar to that described in other accounts ${ }^{11}$. Other organs appeared normal in size and number for a juvenile snake. Lack of hemipenes indicated that the rattlesnake was female. Pathological findings indicate that the rattlesnake starved to death. It seems likely that the anatomical abnormalities, and the disruption of normal physiology they 


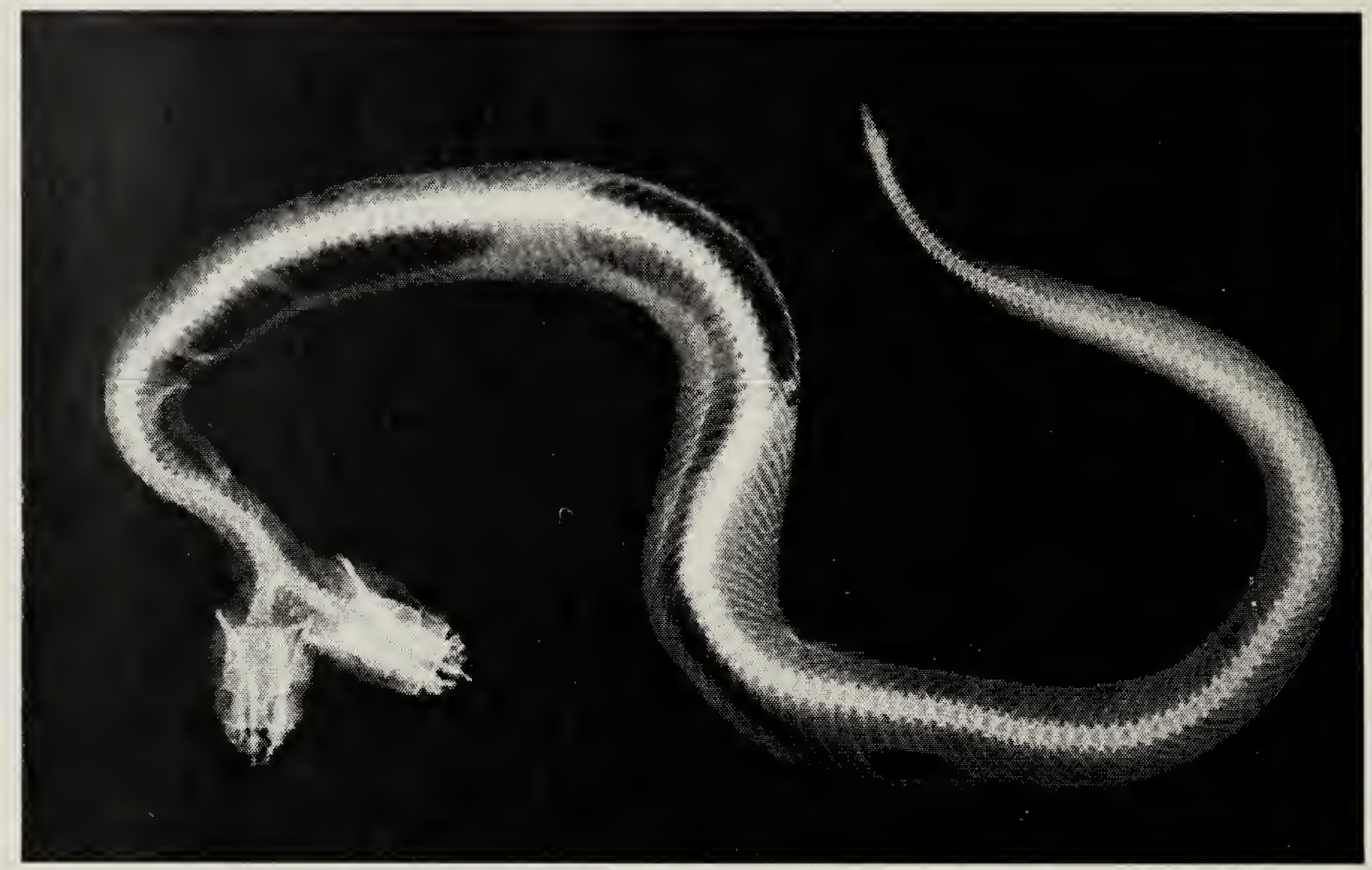

Figure 3. Radiograph of two-headed Prairie Rattlesnake

Ian Shirley

would have caused, combined to prevent this snake from being able to eat. $^{4}$

Bicephalism (two heads) does not seem to be an uncommon birth defect among snakes ${ }^{7,11}$ Klauber described a bicephalic rattlesnake captured in Medicine Hat in 1949. This snake had two heads and necks that were divided for just over $7 \mathrm{~cm}$ before fusing into a common body; while both heads were aware and independent, the snake was unable to coil or move. ${ }^{9}$ Lasher (1980) reports a bicephalic timber rattlesnake (Crotalus horridus) that was born in captivity to a female collected from Alabama; the litter consisted of fully developed young and three infertile eggs. The right head of the bicephalic individual was missing a left eye, and the connection between the heads was so close to the base of the skull the heads were deviated laterally. Lasher cites several other instances of bicephalism in rattlesnakes, most from former subspecies of Crotalus viridis. Mitchell and Fieg report a juvenile Northern
Copperhead (Agkistrodon contrortrix mokasen) from Viginia, USA, that had a similar pattern of bicephalism with both heads joined at the neck just behind the base of the skull. ${ }^{8} \mathrm{X}$ radiography showed that the left head was on the primary vertebral axis while the right one joined five vertebrae below the right skull. In addition to scientific reports, the popular media reports about one case of bicephalism in snakes a year. In fact, the same October, a $60 \mathrm{~cm}$ long bicephalic grass snake (species undefined) was reported in China, ${ }^{1}$ and in 2002 a bicephalic Ladder Snake (Rhinechis scalaris) hatchling was recovered in Spain. $^{2}$

Other congenital defects have been reported in rattlesnakes. Pendlebury gives an account of congenital defects in a litter of aborted fetuses from a female Prairie Rattlesnake captured near Empress, $A B .{ }^{9}$ While none of the snakes exhibited bicephalism, skeletal and organ abnormalities relating to improper fusion or division of organs, as well as skeletal 
abnormalities, did occur in some of fetuses. Pendlebury attributed this to environmental conditions, particularly low temperature during gestation, as the female was not permitted to bask and a high temperature may be necessary for certain stages of embryonic development. ${ }^{9}$

1. ANONYMOUS. Two-headed snake found. 2004. China View News, Xinhuanet. October 21. http:// www.beijingportal.com.cn/7838/2004/ 10/21/207@2333847.htm

2. ANONYMOUS. Two-headed snake found. 2002. BBC News. April 4. http:/ /news.bbc.co.uk/1/hi/sci/tech/ 1910471.stm

3. CLARK, RW. 2004. Kin Recognition in Rattlesnakes. Proceedings of the Royal Society of London B Biological Sciences. May 7; 271 Supplement 4: S243-5

4. FUNK, R.S. 1996. Anorexia. In: Reptile Medicine and Surgery. Douglas Mader. (ed.) W.B. Saunders; Phildelphia, PA: 346-348.

5. JONES, A. 2004. Snakes in Saskatchewan. Environment Newline, Saskatchewan Environment. October
21. http://www.se.gov.sk.ca/media/ Saskatchewan\%20Environmentnewsline/ snakes.htm

6. LASHER, D.N. 1980. A bicephalic Crotalus horridus from Alabama. Herpetological Review. 11(4): 89

7. MAYELL, H. 2002. Life is confusing for two-headed snakes. National Geographic Kid's News. March 22. http://news.nationalgeographic.com/

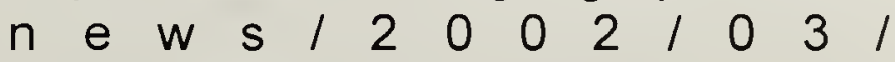
0322_020322_kidsnake.html

8. MITCHELL, J.C. and M. FIEG. 1996. Agkistrodon contortrix mokasen (Northern Copperhead) Bicephaly. Herpetological Review 27(4): 202-203.

9. PENDLEBURY, GB. 1976. Congenital defects in the brood of a prairie rattlesnake. Canadian Journal of Zoology. 54: 2023-2025.

10. RAHN, H. 1942. The reproductive cycle of the prairie rattler. Copeia, 1942(4): 233-240.

11. WALLACH, V. 1995. New records of dicephalic snakes in museum collections. Herpetological Review. 26(3): 127-129.

"As the moths around a taper,

As the bees around a rose,

As the gnats around a vapour,

So the spirits group and close

Round about a holy childhood, as if drinking its repose."

E. B. Browning, A Child Asleep, printed in The Moth Book by W. J. Holland, 1903 (reprinted 1968). 